\title{
Recognition and Thinking on the Teaching Mode of "Commercial Photography" in Higher Art Institutes
}

\author{
Yihan Jia \\ Lecturer of Beijing Institute of Fashion Technology \\ Beijing, 100029, China
}

\begin{abstract}
Photograph is playing an important role in current society, shaping the visual and cultural era centered with visual pictures; under the opportunity of the new era, commercial photography is faced with a number of topics like discussing changing teaching concepts and methods, and improving teaching effects. With the help of research analysis, this paper started from the characteristics of Commercial Photography and current students of higher art institutes, made specific analysis, research and gradual test in practical teaching, and realized good teaching effect.
\end{abstract}

Keywords-art; commercial photography; practical teaching; teaching methods

\section{INTERDISCIPLINARY INTEGRATION HAS ENRICHED THE COURSE}

Along with the development of Internet technology, electronic imaging technology and digital media technology, modern human society has stepped into the era of visual picture reading from previous text reading. Visual pictures have been available in every corner around the world; [1]photography is integrated with modern visual media like movie, TV and cartoon, as well as art creation carriers like drawing, sculpture, art design and game, all of which are shaping the visual culture times with the center of visual pictures.

It is used to spread information for consumers no matter it is in the development of modern social and commercial economy, or on the various e-commerce sales platforms such as Taobao, Tianmao and Jingdong, or all kinds of mobile we-media like Toutiao and Douyin. It is close to people's life, promoting development and communication, which cannot exist without commercial photography. Commercial photography has drawn the wide attention of the public. It has proved that only constant innovation can accelerate the development of commercial photography, so a related course in art colleges should keep pace with the development of the era.

Particularly, under the mode of training comprehensive professional talents with high quality, the topics of discussing changing teaching concepts and methods, and improving teaching effects should be highlighted. Meanwhile, it should be made planned and targeted improvement based on the specific characteristics of each discipline to form a better teaching mode which can adapt to the demand of social and economic development, and match the characteristic of Commercial Photography. Then I will share some thoughts on the practical teaching of Commercial Photography in art colleges based on my practical teaching for many years.

\section{A. The integration of business and art is an important characteristic of commercial photography}

By means of reflecting the shape, structure, quality, color and function of goods as well as the high-quality pictures, commercial photography, regarding goods, enterprises or service as the main objectives,[2] can stimulate customers' senses, aspire their desire to buy something, and finish the shopping. Therefore, commercial photography is a significant method to spread the information of enterprises, service and goods, and promote commodity circulation.

It is a subject with rather strong integration between technology and art. Its technology is reflected by the common camera equipment, lighting equipment, camera lens, light control and shooting techniques in the photography; while its art is reflected in its artistic appeal as a form of language in the picture composition, shooting angle, color expression, artistic atmosphere, lens language and other aspects.[3] It's the close integration that can create such high-quality advertising photography.

At present, the following two teaching modes are widely used in college commercial photography teaching: [4]the first one focuses on photography techniques, which simply regards commercial photography as the most real record with products. It emphasizes the role of photography techniques in commercial photography. Generally, it is according to the sequence of basic photography teaching, and it pays attention to describing and expressing the external characteristics of goods to make them manifested clearly and completely. In terms of the photography techniques, it is perfect, however, the feeling given by the photography works is not infectious enough, so it is hard to make consumers have the same feeling and buy something. The other is oriented with art, which is treated as their assessment standard with photography works. Modern art photography, the fifth art category, emphasizes too much on the picture composition, color expression, and artistic style and conception of photographers. Advertising photography, aiming at selling goods, is a second visual creation on the basis of creative planning. While commercial photography is to induce consumption by means of visualizing images. When commercial photography becomes artistic works, then there will exist numerous possibilities to interpret photography works, failing to achieve the original goals of persuading, inducing and buying. However, both the two sides ignore the demand for commercial goods with photography 
and then weaken the spreading effect of commercial photography works.

Therefore, in the practical teaching of Commercial Photography, it is not appropriate to just emphasize the photography techniques or mere artistic elements, but start from the essence of commercial photography and integrate the inner quality of goods with the external form of commercial photography to form a unified whole.[5] They should be organically connected to train students with their advertising creation by means of technology within limit courses.

B. Commercial Photography is closely integrated with advertising, marketing, aesthetics, color, consumer psychology, and other disciplines

Commercial photography relies on economic activities, whose ultimate purpose is to create strong visual images to draw the consumers' attention, promote goods sale and establish enterprise brand images, rather than foster aesthetics or help artists to make art creation. Therefore, work before photography becomes most important in advertising photography. They must master the existed advertising and marketing policies and plans, the market orientation of photography products, the psychological characteristics of consumers, the creative strategies of advertisement, the competitors of goods, and the feature of composition, optics and media. As Mr. Wen Yiduo said, "dance in chains" in advertising photography. The width and difficulty of advertising photography teaching have been increased in the existed orientation and the limit of planning schemes.

Thus, art college commercial photography should, on the basis of mastering photography thesis. Adapt to the development of current times, consider the interdisciplinary disciplines like advertising, planning, marketing and aesthetics, art, and consumer psychology, and integrate them with the whole commercial operation system, which including planning, orientation, shooting and post promotion.

\section{Strengthen the Aesthetic Abilities and Train the SELF-Creation ABILITIES IN PRACTICAL TEACHING}

\section{A. Imitating classics is an effective method in commercial photography}

All the most excellent classics in the world are polished by years and precipitated down; for example, the picture composition, shadow modeling and color expression of classic paintings and photography works are incomparable in other art forms.

The classic form of light in photographic art, "Rembrandt light", refers to the technique of light form, light ratio and light bit treatment in oil paintings of Rembrandt, a Dutch artist in the Renaissance period; [6]it is a classic way of light using in modern photography. Imitating classics can get the twice result in advertising photography teaching. Firstly, the picture composition and light and shadow distribution of classics can lay solid foundation for students' learning; secondly, the creative thinking in classic art can give commercial photography creation a new inspiration; at last, learning classics can help students solve the problem of being at loss and blindly shooting at the beginning of practical photography.

\section{B. Making the class teaching more interesting and students more active}

The enclosed two-part teaching method, from the theory to the practice, is widely used in college photography teaching. Firstly, teachers explain the basic theories of photography in class, but students' learning interest and enthusiasm are greatly reduced by the boring theoretical knowledge, dull principles and formulas, and learning difficulty, which is not the photography class they have looked forward to. As a result, the later practical shooting is affected.

Commercial photography aims at stimulating people's senses and realizing the sale by means of visual pictures. It requires that we can adopt some methods to make the class more lively and students more active and positive. For teachers, they should introduce classic photography works and cases into the class through PPT, pictures or videos, strengthen direct teaching, and enhance students' photography level and aesthetic ability by analyzing classic cases.

\section{Paying attention to training students' aesthetic abilities and self-assessing their works}

Particularly, those fresh students haven't formed their own recognition due to enough practice with picture composition, light and shadow and techniques, so they dare not sift or assess their own works. They are accustomed to asking for teachers' help. In order to change students' such passive situation, I adopt the following measures: firstly, students are supposed to clearly write shooting time, various parameter setting and shooting topics when handing in photography works. Then, all the students are divided into several teaching groups. Group members should assess each work, pointing out the advantages and disadvantages. As for the controversial work, the whole class will have a specific discussion. Finally, teachers should have a unified explaining and evaluation with excellent works. By means of such teaching mode, students can form their own aesthetic and actively express their viewpoints, changing into positive learning from passive learning; in addition, work assessment and mutual discussion are beneficial to students' appreciation ability and aesthetic thinking, also augmenting their confidence and controlling ability with images.

\section{Industry elites and experts are introduced into the classroom to have a macro mastering with the current development of photography}

During the class teaching, teachers are supposed to give students practical guidance at the film studio so that students can have a better understanding of shooting procedures and methods of commercial photography. What's more, some excellent and successful advertising photographers can be invited to school, who can carry with their own works, give a specific lecture in class, communicate with students face to face, solve their doubts, and promote their recognition with the development status, future prospect, and malignant photography. All of these can lay a solid foundation for students in their future work. After the whole course, students' excellent photography works will be exhibited in colleges to promote students' self-awareness with their own photography level, and increase the positiveness and initiative with commercial photography learning. 


\section{THE TEACHING OF COMMERCIAL PHOTOGRAPHY HAS PUT FORWARD HIGHER REQUIREMENTS FOR COLLEGE TEACHERS}

The times of commercial photography determine its characteristics of keeping pace with the era; their multi-level and multi-disciplinary intersections have also put forward higher requirements for teachers. They are supposed to equip with shooting techniques, artistic aesthetics, progressive vision, professional knowledge, and mastering with the whole operation process of commercial advertisements. Otherwise, teaching will be separated from "commercial", failing to achieve prospected effects of commercial photography. So teachers should constantly improve their own professional qualities, learn professional knowledge, and deepen their theoretical and professional qualities so as to keep pace with times and better adapt to the demand of teaching development.

\section{CONCLUSION}

Commercial photography is of strong practice, and it integrates commercial operation system on the basis of mastering basic theories. It promotes that strategic teaching mode is the development direction of future commercial photography in art institutes.
In the theory teaching, shooting techniques and art should be organically combined. And numerous methods should be adopted to strengthen practical commercial photography like explaining lots of classic photography work cases, imitating classics, teacher lectures, and self-evaluation. By means of such pleasant methods, students can skillfully master the knowledge of commercial design, improve their positiveness and initiative, and promote their artistic qualities and appreciation abilities.

\section{REFERENCES}

[1] Sun Chonghui. The comparison and development trend of photography techniques under the background of new era.[M]. Shanghai Normal University.

[2] https://baike.baidu.com/item/Product Photography/6901584?fr=aladdin

[3] Feng Jianguo. Black and white photography.[M]. Zhejiang. Zhejiang Photography Press.

[4] Xie Jiafeng and Zhao Hoa. Exploration of strategic teaching mode of advertising photography courses. Journal of Nanjing University of Arts(the edition of art and design).

[5] (US)Christopher. Xu Weiguang, translator. Light guide of portrait photography: available for digital and film photographers [M] Changsha. Hunan Fine Arts Publishing House.

[6] http://academy.fengniao.com/426/4269154.html 